\title{
Effect of Silicon on the Desulfurization of Al-Killed Steels: Part II. Experimental Results and Plant Trials
}

\begin{abstract}
DEBDUTTA ROY, PETRUS CHRISTIAAN PISTORIUS, and RICHARD J. FRUEHAN
Recent observations suggest that increased silicon levels improve ladle desulfurization of aluminum-killed steel. A kinetic model was developed and presented in part I of this paper, demonstrating that increased silicon levels in steel suppress the consumption of aluminum by parasitic reactions like silica reduction and $\mathrm{FeO} / \mathrm{MnO}$ reduction, thus making more aluminum available at the interface for desulfurization. The results are increases in the rate and the extent of desulfurization. Predictions were compared with laboratory induction furnace melts using $1 \mathrm{~kg}$ of steel and $0.1 \mathrm{~kg}$ slag. The experimental results demonstrate the beneficial effect of silicon on the desulfurization reaction and that alumina can be reduced out of the slag and aluminum picked up by the steel, if the silicon content in the steel is high enough. The experimental results are in close agreement with the model predictions. Plant trials also show that with increased silicon content, both the rate and extent of desulfurization increase; incorporating silicon early into the ladle desulfurization process leads to considerable savings in aluminum consumption.
\end{abstract}

DOI: $10.1007 / \mathrm{s} 11663-013-9888-7$

(C) The Minerals, Metals \& Materials Society and ASM International 2013

\section{INTRODUCTION}

PART I of this two-part paper presented the background to this work, including the kinetic model used to predict the effect of silicon on ladle desulfurization. ${ }^{[1]}$ In this paper, experimental results are presented which test the effect of silicon on the rate and the extent of desulfurization of aluminum-killed steels in contact with slags of different compositions. Plant trials were conducted in collaboration with an electric arc furnace (EAF) steel producer and the results analyzed to test the silicon effect on desulfurization.

\section{EXPERIMENTAL SETUP AND PROCEDURE}

\section{A. Experimental Setup}

Experiments were run using a $10-\mathrm{kW}$ radio frequency induction furnace; a schematic of the experimental setup is shown in Figure 1. The liquid steel was contained in a magnesia crucible $(0.049 \mathrm{~m}$ ID, $0.062 \mathrm{~m}$ OD, $0.15 \mathrm{~m}$ high) surrounded by a graphite crucible $(0.064 \mathrm{~m} \mathrm{ID,}$ $0.07 \mathrm{~m} \mathrm{OD}, 0.14 \mathrm{~m}$ high). The graphite crucible served as a susceptor to heat and melt the steel and slag and also served as a protective outer crucible. A magnesia crucible

DEBDUTTA ROY, formerly Graduate Student with the Department of Materials Science \& Engineering, Center for Iron and Steelmaking Research, Carnegie Mellon University, 5000 Forbes Avenue, Pittsburgh, PA 15213, is now Research Engineer at SaintGobain Abrasives, Worcester, MA. PETRUS CHRISTIAAN PISTORIUS, Professor, and RICHARD J. FRUEHAN, US Steel Professor, are with the Department of Materials Science \& Engineering, Center for Iron and Steelmaking Research, Carnegie Mellon University. Contact e-mail: pistorius@cmu.edu

Manuscript submitted October 2, 2012.

Article published online June 14, 2013. was chosen to simulate the industrial conditions for desulfurization, where ladles typically have $\mathrm{MgO}$ bricks at the slagline. The reaction chamber which contained the magnesia and graphite crucibles was a fused-quartz tube, $0.5 \mathrm{~m}$ high, $0.08 \mathrm{~m} \mathrm{ID}$, and $0.085 \mathrm{~m} \mathrm{OD}$, sealed airtight at the top and bottom using clamped end caps. Argon gas (99.9 pct pure, passed over heated magnesium to getter oxygen) was introduced into the reaction chamber through a gas inlet in the lower end cap; the gas flow rate was maintained at the same value from experiment to experiment with the aid a flow meter. A mullite guide tube (ID $0.0127 \mathrm{~m}$, OD $0.0196 \mathrm{~m}$ ), attached to a port in the top seal, facilitated additions during the experiment and sampling. The temperature of the melt was measured using two alumina-sheathed type $\mathrm{S}$ thermocouples; one was introduced through the lower end cap and with its tip at the bottom of the graphite crucible, and the other was introduced through the upper end cap to measure the temperature at the top surface of the melt (until just before slag addition).

The steel used in the experiments was industrial material which was chosen to have low levels of impurities and alloying elements (see the composition in Table I). Slag was prepared by mixing reagent grade powders $\left(\mathrm{CaO}, \mathrm{MgO}, \mathrm{SiO}_{2}, \mathrm{Al}_{2} \mathrm{O}_{3}\right)$ and premelting the slag in a graphite crucible in flowing argon. The liquidus temperatures of the slag compositions were calculated using FactSage ${ }^{[2]}$ to be approximately $1820 \mathrm{~K}$ (approximately $1550{ }^{\circ} \mathrm{C}$ ), and so the slag powders were heated to $1873 \mathrm{~K}\left(1600{ }^{\circ} \mathrm{C}\right)$ and allowed to homogenize for around 30 minutes at the temperature. Once cooled, the slag was crushed and ground to fine powder which was used as premelted slag additions during the desulfurization reaction. For every experiment, a steel to slag mass ratio of 10:1 was maintained, so $0.1 \mathrm{~kg}$ of slag was added to the steel melt in each experiment. 


\section{B. Experimental Procedure}

The experimental procedure consisted of the following steps:

(1) Argon was flowed through the reaction chamber to flush out remnant oxygen that could be present in the chamber.

(2) A steel block weighing approximately $1 \mathrm{~kg}$ was melted using the induction furnace. The temperature was monitored using both thermocouples.

(3) Once the steel block was molten, alloying additions (aluminum shot, ferrosilicon, and iron sulfide) were added to the molten steel to reach the desired starting chemistry for the experiment. Initial compositions are listed in Table III.

(4) A homogenization time of 15 minutes was allowed, while maintaining the temperature at $1873 \mathrm{~K}\left(1600{ }^{\circ} \mathrm{C}\right)$.

(5) The steel melt was sampled with a fused-quartz tube (0.004 $\mathrm{m}$ ID, $0.00635 \mathrm{~m}$ OD) to determine the initial composition of the steel melt. Premelted slag of known composition $(0.1 \mathrm{~kg})$ was then added to the steel melt. Time zero was taken as the instant when the premelted slag was added. Once the premelted

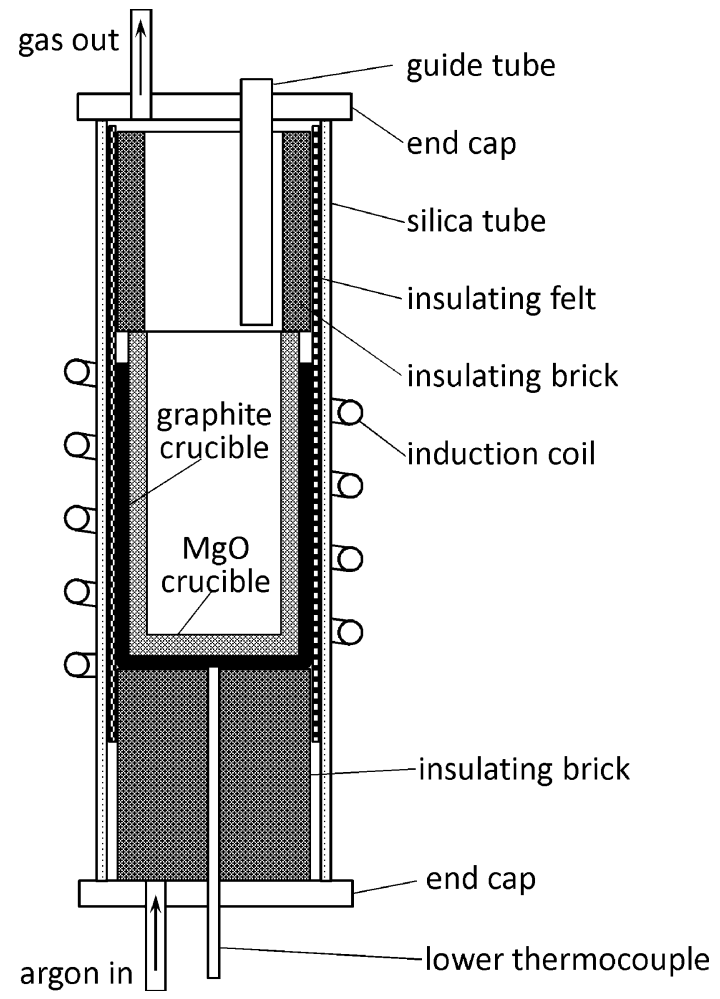

Fig. 1-Schematic of the experimental setup. slag had been added to the molten steel, the upper thermocouple could no longer be used to record the temperature of the melt surface (because its alumina sheath would dissolve in the slag); the lower thermocouple was used monitor the temperature of the melt during the desulfurization reaction.

(6) After adding the slag, the steel melt was sampled at regular intervals with fused-quartz tubes; the steel samples were subsequently analyzed (using the inductively coupled plasma technique for aluminum and silicon, and combustion analysis for sulfur and total oxygen analysis; in each case, the entire sample was analyzed to obtain an average composition). The soluble aluminum content was estimated by subtracting the aluminum bound to oxygen from the analyzed total aluminum content (using the analyzed total oxygen content, and assuming all inclusions to be alumina); total oxygen contents were in the range 45 to 100 ppm for all runs.

\section{Slag and Steel Compositions}

A series of parametric studies carried out on the model

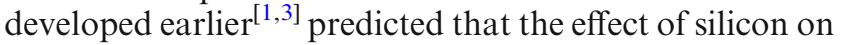
desulfurization would be more pronounced for slags with lower basicity than for slags with higher basicity (basicity here refers to the $\mathrm{CaO} / \mathrm{Al}_{2} \mathrm{O}_{3}$ ratio). The experiments hence used three different slag compositions which differed mainly with regards to their $\mathrm{CaO} / \mathrm{Al}_{2} \mathrm{O}_{3}$ ratio; the three slag compositions are tabulated in Table II. Slags were chosen to be magnesia saturated (the required $\mathrm{MgO}$ content was calculated using FactSage ${ }^{[2]}$ ).

For each slag composition, experiments were performed for two different initial silicon contents as tabulated in Table III (keeping the initial Al and $\mathrm{S}$ contents approximately the same).

\section{RESULTS AND DISCUSSION}

\section{A. Fitting the Kinetic Model to the Experimental Results}

In industrial ladle desulfurization, stirring the melt (by gas or induction stirring) is used to achieve workable

Table II. Slag Compositions Used in the Experiments (Mass Percentage)

\begin{tabular}{lccrr}
\hline & $\mathrm{CaO}$ & $\mathrm{Al}_{2} \mathrm{O}_{3}$ & $\mathrm{SiO}_{2}$ & $\mathrm{MgO}$ \\
\hline High basicity & 51.7 & 36.2 & 5.3 & 6.8 \\
Medium basicity & 48.5 & 32.5 & 10.1 & 8.3 \\
Low basicity & 39.9 & 39.7 & 8.9 & 11.1 \\
\hline
\end{tabular}

Table I. Chemical Composition (Mass Percentage) of the Steel Block Used in the Experiments

\begin{tabular}{lccccrr}
\hline $\mathrm{C}$ & $\mathrm{Al}$ & $\mathrm{S}$ & $\mathrm{Si}$ & $\mathrm{Mn}$ & $\mathrm{Ti}$ & $\mathrm{Cu}$ \\
\hline 0.0028 & 0.026 & 0.008 & 0.004 & 0.077 & 0.051 & 0.045 \\
\hline $\mathrm{Ni}$ & $\mathrm{V}$ & $\mathrm{Co}$ & $\mathrm{Cr}$ & $\mathrm{P}$ & $\mathrm{Mo}$ & $\mathrm{N}$ \\
\hline 0.014 & 0.002 & 0.002 & 0.037 & 0.007 & 0.007 & 0.0027 \\
\hline
\end{tabular}


desulfurization rates. In the experimental setup, the graphite crucible shielded the melt from inductive stirring, but natural convection did cause flow, as demonstrated by the observed change with time (Figures 2 through 4).

The kinetic model developed earlier ${ }^{[1,3]}$ was used to analyze the results of the laboratory experiments. A simplified model, considering only mass transfer of $\mathrm{Al}$, $\mathrm{Si}$, and $\mathrm{S}$ in the steel as potentially rate determining, was used since slag mass transfer was not expected to be rate limiting. (The simplified model was executed considerably faster than the full mixed-control model.) Reaction

Table III. Starting Compositions of Steel

\begin{tabular}{lccc}
\hline Slag No & {$[\text { Pct Si }]_{0}$} & {$[\text { Pct Al }]_{0}$} & {$[\text { Pct S }]_{0}$} \\
\hline HB1 (high-basicity slag) & 0.009 & 0.052 & 0.024 \\
HB2 (high-basicity slag) & 0.91 & 0.051 & 0.025 \\
MB1 (medium-basicity slag) & 0.039 & 0.047 & 0.018 \\
MB2 (medium-basicity slag) & 0.77 & 0.052 & 0.017 \\
LB1 (lower-basicity slag) & 0.039 & 0.038 & 0.019 \\
LB2 (lower-basicity slag) & 1.9 & 0.031 & 0.019 \\
\hline
\end{tabular}

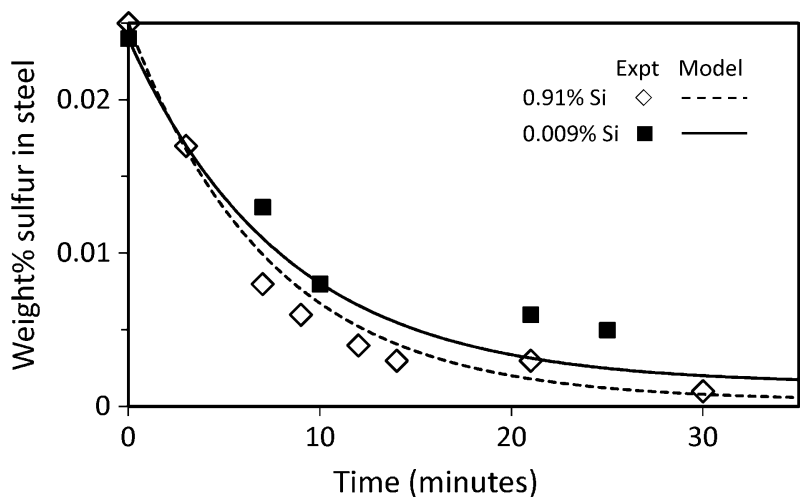

Fig. 2-Highest-basicity slag: experimental data (points) and model prediction (lines) of change of sulfur content with time for two different Si contents in the steel. Weight of steel/weight of slag $=10$. Slag composition: 51.7 pet $\mathrm{CaO}, 36.2$ pet $\mathrm{Al}_{2} \mathrm{O}_{3}, 5.2$ pct $\mathrm{SiO}_{2}, 6.8$ pct $\mathrm{MgO}$.

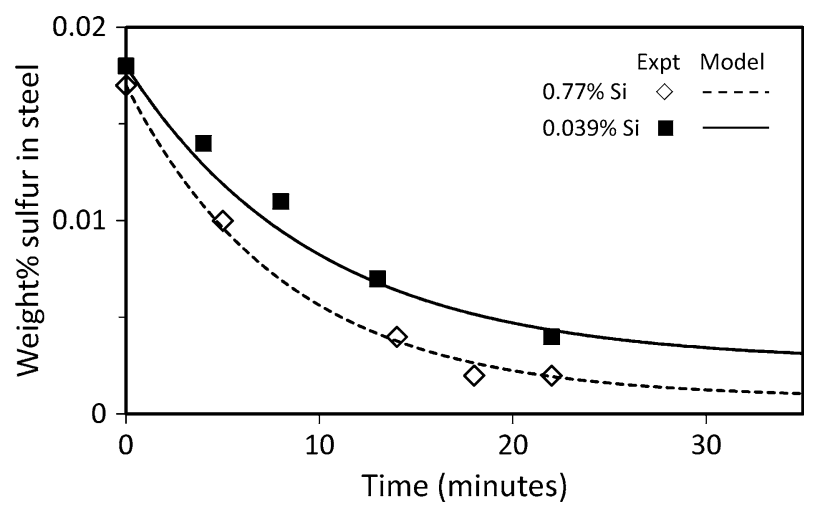

Fig. 3-Medium-basicity slag: experimental data (points) and model prediction (lines) of change of sulfur content with time for two different $\mathrm{Si}$ contents in the steel. Weight of steel $/$ weight of slag $=10$. Slag composition: 48.5 pct $\mathrm{CaO}, 32.5$ pct $\mathrm{Al}_{2} \mathrm{O}_{3}, 10.1$ pct $\mathrm{SiO}_{2}$, 8.3 pet $\mathrm{MgO}$. equilibria were calculated using slag activity coefficients from the FactSage SlagA model ${ }^{[2]}$ (for calculating the $\mathrm{Si}$ / $\mathrm{SiO}_{2} / \mathrm{Al} / \mathrm{Al}_{2} \mathrm{O}_{3}$ reaction and the resulting oxygen activity at the slag-steel interface) and employing the $\mathrm{KTH}$ sulfide capacity model. ${ }^{[4]}$ The only adjustable parameter when fitting the model to the experimental results was the effective mass transfer coefficient (mA). A single mass transfer coefficient was fitted to all the experimental results, with the exception of the run with the low-Si, low-basicity slag case (LB1). The experimental data for each experiment were fitted to the model results using three different $\mathrm{mA}$ values $\left(0.15,0.2\right.$, and $\left.0.25 \mathrm{~cm}^{3} / \mathrm{s}\right)$ and the sum of the absolute errors calculated for each $\mathrm{mA}$ value (Figure 5). Overall, $\mathrm{mA}=0.2 \mathrm{~cm}^{3} / \mathrm{s}$ was the bestfit mass transfer coefficient for all the experimental data (Table IV), except the experiment with low slag basicity and low Si. In the latter experiment, the sulfur distribution coefficient was small, causing slag mass transfer to be partially limiting, as explained later. Since mass transfer in the metal was rate determining for all cases except LB1 (in which case, the sulfur distribution coefficient was relatively small), a single mass transfer coefficient was used for all conditions except LB1.

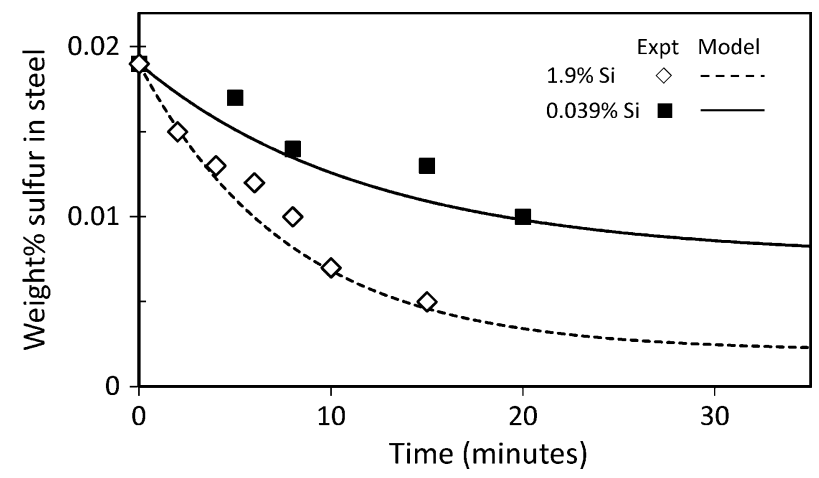

Fig. 4-Lowest-basicity slag: experimental data (points) and model prediction (lines) of change of sulfur content with time for two different Si contents in the steel. Weight of steel/weight of slag $=10$. Slag composition: 39.9 pet $\mathrm{CaO}, 39.7$ pct $\mathrm{Al}_{2} \mathrm{O}_{3}, 8.9$ pct $\mathrm{SiO}_{2}$, 11.1 pet $\mathrm{MgO}$.

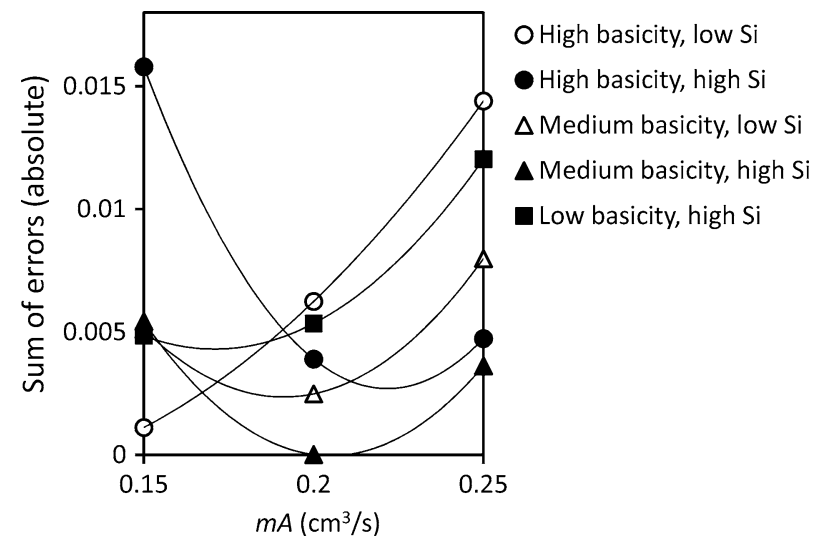

Fig. 5-Absolute sum of errors for different values of the kinetic $(\mathrm{mA})$ parameter used when fitting the model results to the experimental datasets. In each case, the error is the difference between the calculated and predicted sulfur content (mass pct). 
Table IV. "Best-Fit” Mass Transfer Coefficient Values (mA) for Laboratory Runs

\begin{tabular}{lc}
\hline Experiment & $\mathrm{mA}\left(10^{-6} \mathrm{~m}^{3} / \mathrm{s}\right)$ \\
\hline HB1, HB2, MB1, MB2, and LB2 & 0.2 \\
LB1 (lower-basicity slag, low Si) & 0.1 \\
\hline
\end{tabular}

(Figure 5 does indicate that for the case with high slag basicity and low $\mathrm{Si}$, a better fit to the experimental data would have been obtained by employing a somewhat smaller mass transfer coefficient, but there is no clear fundamental reason to adopt such a decreased value in this case.)

The kinetic model was based on mass transfer control, coupled with information on all slag-metal reactions involving $\mathrm{Al}, \mathrm{O}, \mathrm{Si}$, and $\mathrm{S}$. When comparing the model predictions and experimental data (as shown later in this paper), it is important to note that the model predictions are not curve fits to the experimental data. The only form of curve fitting that was performed was to estimate the mass transfer coefficient, as described above.

While the only fitting parameter in the model was the mass transfer coefficient, the model results are sensitive to the choice of $\mathrm{Al}_{2} \mathrm{O}_{3}$ and $\mathrm{SiO}_{2}$ activity data. Previously, Andersson et al. ${ }^{[5]}$ used the expressions of Ohta and Suito ${ }^{[6]}$ to calculate activities of silica and alumina, when modeling ladle desulfurization. In Part I, it was shown that the Ohta and Suito expressions predict very different ratios of silica to alumina activity than the FactSage slag model and that the activities from FactSage fitted experimental data (for $\mathrm{Al}-\mathrm{SiO}_{2}$ reaction) in the literature. ${ }^{[1]}$ The experimental results from the present work also indicate that the FactSage activity data correctly predict the direction and extent of the slag-steel reactions, as illustrated by the comparisons in Figures 6 and 7: While the choice of activity data does not have a large effect on the predicted degree of desulfurization (Figure 6), there is a strong effect on the predicted alumina/silicon reaction (Figure 7). Figure 7 illustrates that the Ohta and Suito expressions do not predict the observed aluminum pick-up by the steel for runs with high-silicon steels, whereas if the FactSage activity are used, the model predictions of the change of aluminum content with time agree with the experimental data for both lowand high-silicon steels.

As Figures 2 through 4 demonstrate, the same value of $\mathrm{mA}$ fitted all the experiments reasonably well (except for the low-basicity, low-Si case, LB1), despite differences in the direction and extent of the $\mathrm{Si} / \mathrm{SiO}_{2} / \mathrm{Al} / \mathrm{Al}_{2} \mathrm{O}_{3}$ reaction (Figures 8 through 10 show that runs with low initial $\mathrm{Si}$ contents showed $\mathrm{Al}$ fade, whereas Al pick-up occurred in the runs with high initial $\mathrm{Si}$ ). In previous work, a reaction between $\mathrm{Fe}-\mathrm{Al}$ melts and silicacontaining slags was reported to result in low dynamic interfacial tension, causing a convoluted slag-steel interface and potential emulsification. ${ }^{[7]}$ There is no evidence that such interfacial effects played a role in these experiments, since the rate constants were similar in all cases (except LB1).

\section{B. Effect of Silicon on Desulfurization}

Figures 2 through 4 show the experimental data and the model results for the change in sulfur content with time, for the three slag compositions, each with two different initial silicon contents in the steel. In all cases, the agreement between the experimental data and kinetic model predictions for the change in sulfur content is quite good. In line with predictions, ${ }^{[1]}$ the experimental data show that both the rate and the extent of desulfurization increase with increasing silicon content and that the effect is much more pronounced in the case of the slag with lowest basicity. In fact for the lowest-basicity slag, the effect of silicon is quite pronounced despite the lower-Si melt initially containing more aluminum $(0.031 \mathrm{wt}$ pct $\mathrm{Al}$ for the high-Si melt compared with $0.038 \mathrm{wt}$ pct $\mathrm{Al}$ for the low-Si melt).

The experimental results for the slag with the lowest basicity and high-Si content (LB2; Figure 4) further emphasize the beneficial effect of silicon: Considerable desulfurization was obtained despite the low $\mathrm{CaO}$ content of this slag. In this experiment, the sulfur content of the steel decreased from 190 to $50 \mathrm{ppm}$ in 15 minutes, using a slag containing only 40 pct lime; sulfur removal was obtained due to the high-silicon content of 1.9 pct. Although such a high-silicon content would be outside the specification range of most steels, this result does emphasize that high-silicon contents do lead to strongly reducing conditions (for the relatively low- $\mathrm{SiO}_{2}$ slags used here).

\section{Change of Aluminum and Silicon Contents with Time}

Figures 8 through 10 plot the change with time in the aluminum contents of steel reacted with the three different slag compositions listed in Table II, for low$\mathrm{Si}$ and high-Si cases; Figures 11 and 12 show the corresponding changes in the Si content, with model predictions. For all the experiments conducted, the directions of changes in the silicon and aluminum contents do agree with model predictions. However, the experimental data are rather scattered. There are two likely contributions to the scatter: First, if a small amount of slag had been entrained in the steel sample, the steel analysis would be high in $\mathrm{Al}, \mathrm{Si}$, and $\mathrm{S}$. Second, the soluble aluminum content was estimated by subtracting aluminum bound to oxygen from the total aluminum analysis. The estimate of bound aluminum hence depends on the total oxygen analysis, which is inherently more variable than the total elemental analysis. A third possibility is a reaction between dissolved aluminum in the steel and the quartz sampler; however, careful examination of the inner surfaces of used sampling tubes and cross sections of steel samples did not show evidence of such a reaction.

The experimental results consistently show aluminum pick-up by the steel, for each case of reaction of the high-silicon steels with slag (Figures 8 through 10). A few slag samples, obtained after cooling the crucible containing steel and slag after 30 minutes of reaction, were analyzed to further test these trends. While the change in slag composition was small, the analyzed silica 
content of the slag did change in the predicted direction (Figure 13). These results confirm that if the silicon content in the steel is high enough, consumption of aluminum by the desulfurization reaction can indeed be suppressed (as the model predicted ${ }^{[1]}$ ). Similarly, the observed change in sulfur content of the slag (Figure 14) agreed reasonably well with the model predictions.

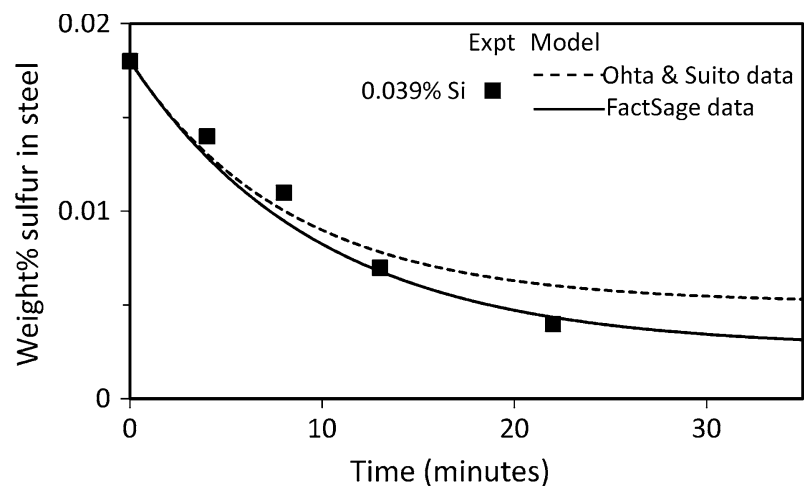

Fig. 6-Experimental data of change of sulfur in steel with time (data points), compared with model results (lines) calculated with activity values taken from FactSage and the Ohta and Suito expressions. Initial silicon content: $0.039 \mathrm{wt}$ pct. Weight of steel/weight of slag $=10$. Slag composition: 48.5 pct $\mathrm{CaO}, 32.5$ pet $\mathrm{Al}_{2} \mathrm{O}_{3}$, 10.1 pet $\mathrm{SiO}_{2}, 8.3$ pet $\mathrm{MgO}$.

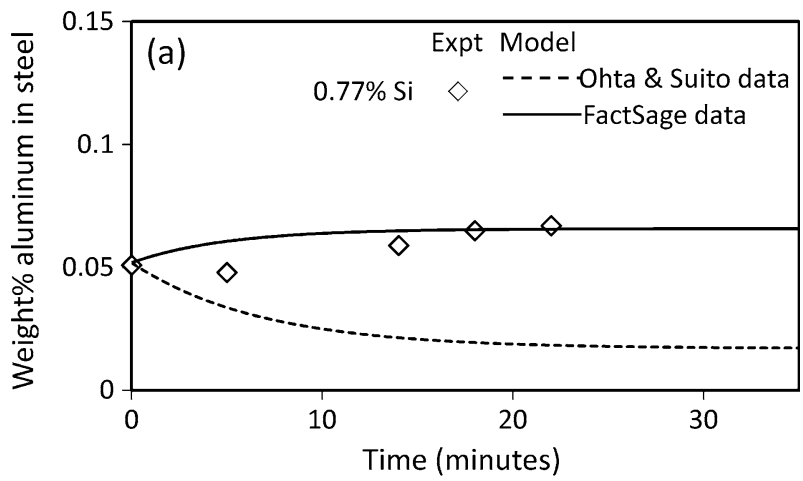

(a)

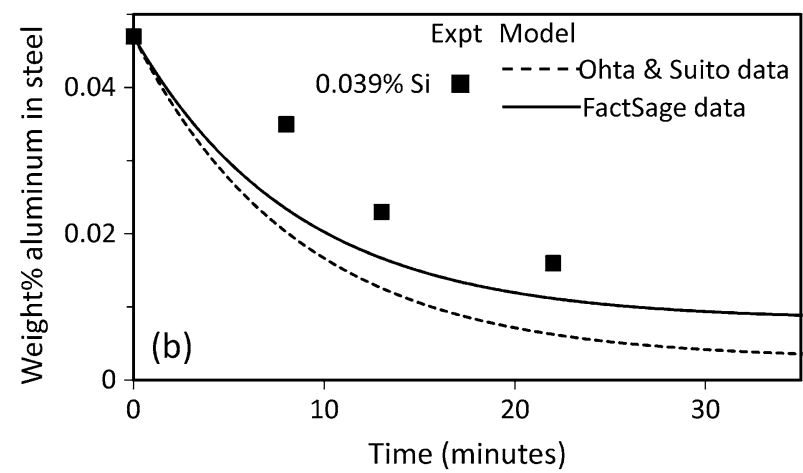

(b)

Fig. 7-Experimental data of change of aluminum in steel with time (data points), compared with model results (lines) calculated with activity values taken from FactSage and the Ohta and Suito expressions. Initial silicon contents: (a) 0.77 wt pet and (b) 0.039 wt pet; slag composition as in Fig. 6.
(Note that, as Figure 14 indicates, the slag was found to contain approximately 0.05 pct sulfur before reaction).

The agreement between the model results and the experimental data gives confidence in the fundamental validity of the developed model. Desulfurization and silica reduction simultaneously consume aluminum at

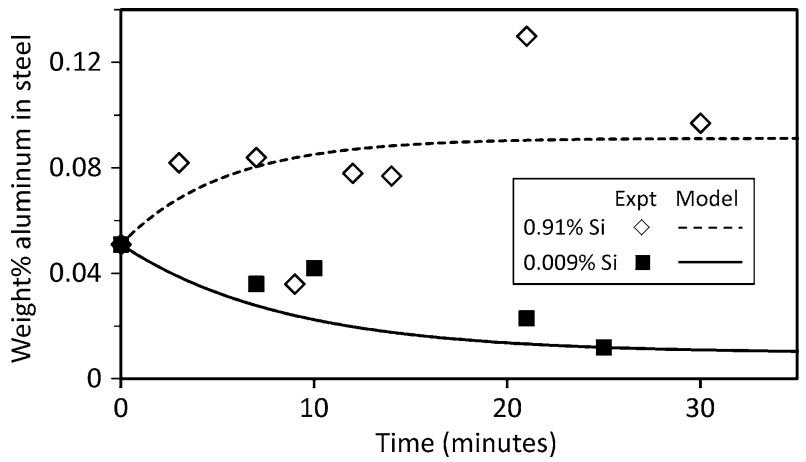

Fig. 8-Highest-basicity slag: experimental data (points) and model prediction (lines) of change of aluminum content with time for two different Si contents in the steel. Weight of steel $/$ weight of slag $=10$. Slag composition: 51.7 pct $\mathrm{CaO}, 36.2$ pct $\mathrm{Al}_{2} \mathrm{O}_{3}, 5.2$ pet $\mathrm{SiO}_{2}, 6.8$ pct $\mathrm{MgO}$.

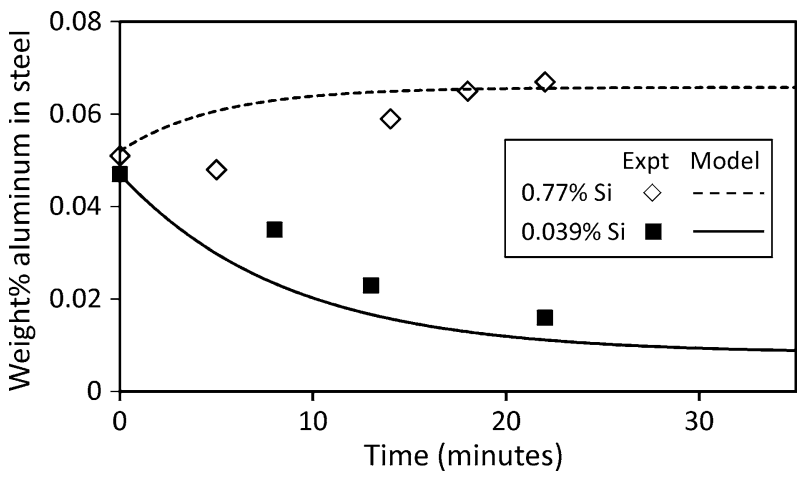

Fig. 9-Medium-basicity slag: experimental data (points) and model prediction (lines) of change of aluminum content with time for two different Si contents in the steel. Weight of steel/weight of slag $=10$. Slag composition: 48.5 pet $\mathrm{CaO}, 32.5$ pet $\mathrm{Al}_{2} \mathrm{O}_{3}, 10.1$ pet $\mathrm{SiO}_{2}$, 8.3 pet $\mathrm{MgO}$.

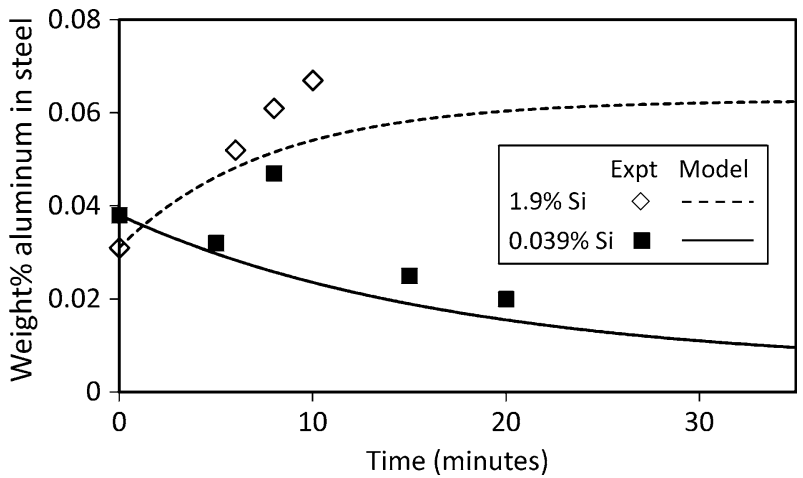

Fig. 10 - Lowest-basicity slag: experimental data (points) and model prediction (lines) of change of aluminum content with time for two different Si contents in the steel. Weight of steel $/$ weight of slag $=10$. Slag composition: 39.9 pet $\mathrm{CaO}, 39.7$ pet $\mathrm{Al}_{2} \mathrm{O}_{3}, 8.9$ pet $\mathrm{SiO}_{2}$, 11.1 pet $\mathrm{MgO}$. 


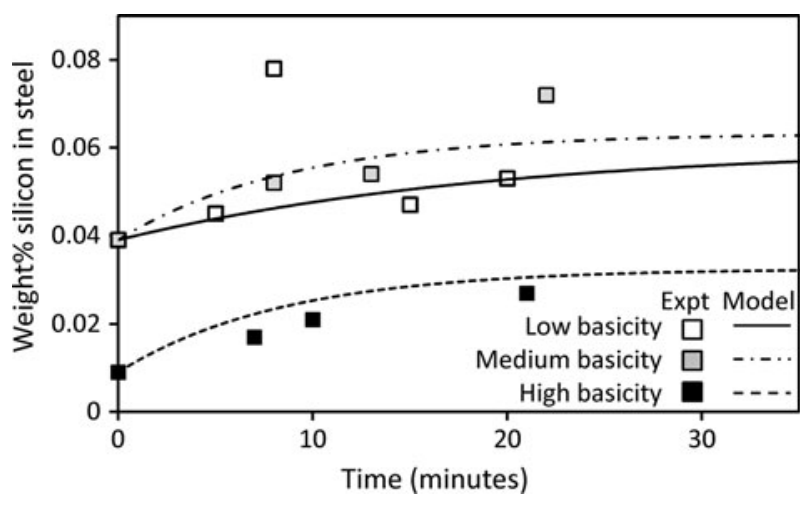

Fig. 11-Steel with low initial silicon content (composition listed in Table III): change of Si with time for reaction of steel with the three slag compositions in Table II. Weight of steel/weight of slag $=10$.

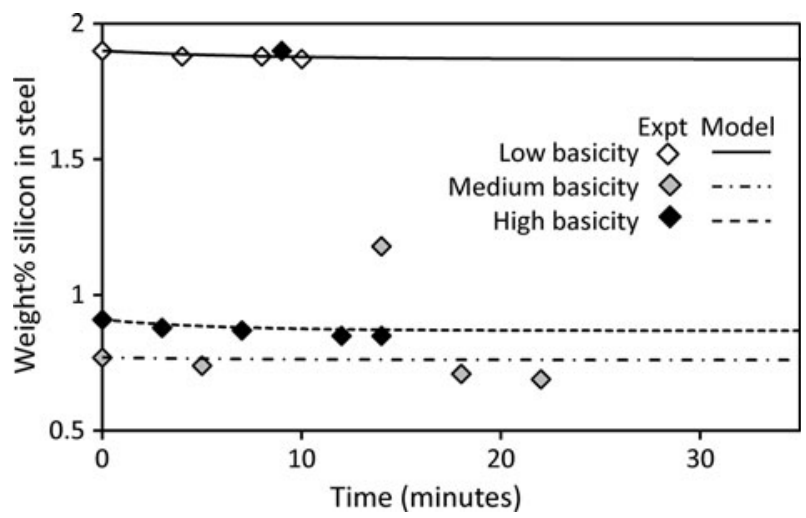

Fig. 12-Steel with high initial silicon content (composition listed in Table III): change of Si with time for reaction of steel with the three slag compositions in Table II. Weight of steel/weight of slag $=10$.

the slag/steel interface. Increasing the silicon content in the steel decreases consumption of aluminum by silica, increasing the aluminum concentration at the slag/steel interface and hence favoring desulfurization. The experimental results confirm that if the silicon content in the steel is high enough, it can indeed suppress consumption of aluminum: In those cases, silicon reduces alumina from the slag, causing aluminum pick-up by the steel melt. The overall mass balances also confirm the dominant effect of silicon/silica on aluminum consumption, as discussed in the next section.

\section{Aluminum Consumption: Mass Balance}

The total aluminum reaching the slag/steel interface from the bulk steel is used for desulfurization reaction, silica reduction, and the reduction of any other unstable oxides, such as $\mathrm{FeO}$ and $\mathrm{MnO}$. In the absence of $\mathrm{FeO}$ and $\mathrm{MnO}$ in the slag (as for the slag compositions considered in the experiments), and if no oxygen enters from the surroundings, the consumption of aluminum is the sum of that from the desulfurization reaction and from silica reduction. From consideration of the

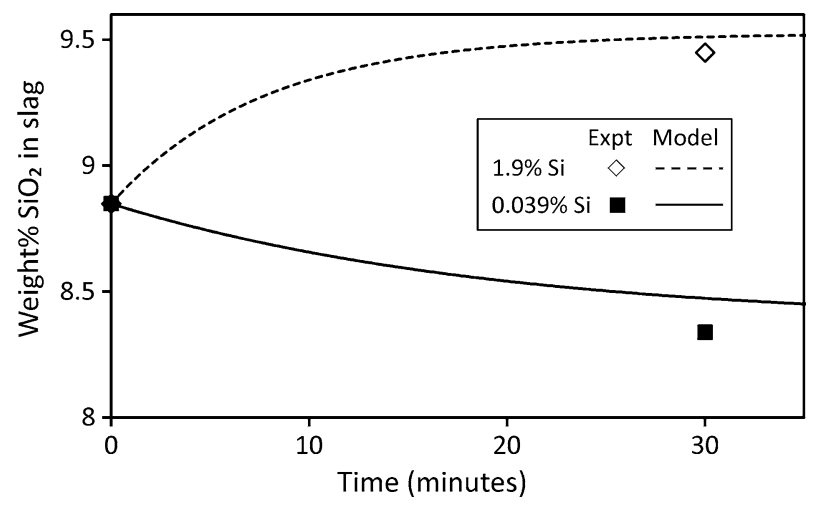

Fig. 13 - Change of silica content in the slag with time for reaction of low-Si and high-Si steel with lowest-basicity slag (39.9 pct $\mathrm{CaO}$, 39.7 pct $\mathrm{Al}_{2} \mathrm{O}_{3}, 8.9$ pct $\mathrm{SiO}_{2}, 11.1$ pct $\mathrm{MgO}$ ). Weight of steel/weight of slag $=10$

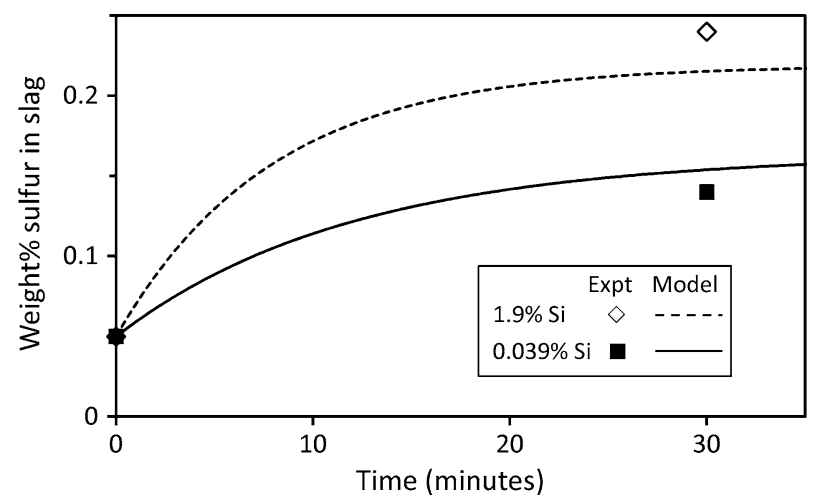

Fig. 14 Change of sulfur content in the slag with time for reaction of low-Si and high-Si steel with lowest-basicity slag (39.9 pet $\mathrm{CaO}$, 39.7 pct $\mathrm{Al}_{2} \mathrm{O}_{3}, 8.9$ pct $\mathrm{SiO}_{2}, 11.1$ pet $\mathrm{MgO}$ ). Weight of steel/weight of slag $=10$.

stoichiometry of the reactions, aluminum consumption is hence given by Eq. [1]:

$$
\Delta n_{\mathrm{Al}}=\frac{2}{3} \Delta n_{\mathrm{S}}-\frac{4}{3} \Delta n_{\mathrm{Si}}
$$

where $\Delta n_{i}$ is the change in the molar amount of species $i$ dissolved in the liquid steel.

Aluminum mass balances for both high and low initial silicon contents are presented in Tables V and VI, respectively; the difference between the calculated combined consumption of aluminum (taking into consideration the silica reduction and desulfurization reactions) and the measured change in aluminum is never more than 30 pct, which appears to be reasonable given the observed scatter in the aluminum and silicon analyses.

The mass balance calculations confirm that aluminum consumption by the desulfurization reaction is smaller than aluminum consumption (or production) by the silica/silicon reaction: Regarding aluminum consumption, desulfurization is the side reaction, whereas silica reduction (or formation) is the main aluminum-consuming (or producing) reaction. This is as predicted in Part I. ${ }^{11}$ 
Table V. Aluminum Mass Balance: Low-Silicon Experiments

\begin{tabular}{|c|c|c|c|c|c|}
\hline Slag Type and Silicon Content & $\begin{array}{c}\text { Aluminum } \\
\text { Consumed } \\
\left(-\Delta n_{\mathrm{Al}}\right)(\mathrm{mol})\end{array}$ & $\begin{array}{l}\text { Silica Reduced } \\
\left(\Delta n_{\mathrm{Si}}\right)(\mathrm{mol})\end{array}$ & $\begin{array}{c}\text { Sulfur } \\
\text { Removed from } \\
\text { Steel }\left(-\Delta n_{\mathrm{S}}\right) \\
(\mathrm{mol})\end{array}$ & $\begin{array}{c}n_{\text {balance }}= \\
(4 / 3) \Delta n_{\mathrm{Si}}- \\
\quad(2 / 3) \Delta n_{\mathrm{S}}\end{array}$ & $\begin{array}{c}\text { Error; } \\
\left(\Delta n_{\mathrm{A} 1}+n_{\text {balance }}\right) / \\
\left(-\Delta n_{\mathrm{Al}}\right)(\mathrm{pct})\end{array}$ \\
\hline High basicity, low silicon ( 0.009 wt pct) & 0.0014 & 0.00064 & 0.00059 & 0.0012 & -13 \\
\hline Medium basicity, low silicon ( 0.039 wt pct) & 0.0009 & 0.00054 & 0.00053 & 0.0011 & 20 \\
\hline
\end{tabular}

Table VI. Aluminum Mass Balance: High-Silicon Experiments

\begin{tabular}{|c|c|c|c|c|c|}
\hline Slag Type and Silicon Content & $\begin{array}{c}\text { Aluminum } \\
\text { Consumed } \\
\left(-\Delta n_{\mathrm{Al}}\right)(\mathrm{mol})\end{array}$ & $\begin{array}{l}\text { Silica Reduced } \\
\quad\left(\Delta n_{\mathrm{Si}}\right)(\mathrm{mol})\end{array}$ & $\begin{array}{c}\text { Sulfur } \\
\text { Removed from } \\
\text { Steel }\left(-\Delta n_{\mathrm{S}}\right) \\
(\mathrm{mol})\end{array}$ & $\begin{array}{c}n_{\text {balance }}= \\
(4 / 3) \Delta n_{\mathrm{Si}}- \\
\quad(2 / 3) \Delta n_{\mathrm{S}}\end{array}$ & $\begin{array}{c}\text { Error; } \\
\left(\Delta n_{\mathrm{Al}}+n_{\text {balance }}\right) / \\
\left(-\Delta n_{\mathrm{Al}}\right)(\mathrm{pct})\end{array}$ \\
\hline High basicity, high silicon ( $0.91 \mathrm{wt}$ pct) & -0.0012 & -0.0014 & 0.00053 & -0.0016 & 27 \\
\hline Low basicity, high silicon (1.9 wt pct) & -0.0011 & -0.001 & 0.0003 & -0.0012 & 6 \\
\hline
\end{tabular}

\section{E. Effect of Slag Phase Mass Transfer on Desulfurization}

The simplified model used to fit the experimental results considered only mass transfer in the steel as a potentially rate-determining step. Figures 2 through 4 (and Table IV) show that the simplified model gives a reasonable fit to the experimental results if the same effective mass transfer coefficient is used in all cases, except for the lowest-basicity, low-Si case (LB1). The same effective mass transfer coefficient is expected in all cases if the sulfur distribution coefficient is sufficiently large, as shown by Eq. [2] $]^{[1]}$ :

$$
m_{\mathrm{eff}}=\frac{m_{\text {steel }}}{1+\frac{m_{\text {steel }}}{m_{\text {slag }}} \frac{\rho_{\text {steel }}}{\rho_{\text {slag }} L}}
$$

where $m_{\text {eff }}$ is the effective mass transfer coefficient, $L$ is the partition coefficient of sulfur between slag and steel, $\rho_{\text {steel }}$ and $\rho_{\text {slag }}$ are the densities of the steel and the slag phases, and $m_{\text {steel }}$ and $m_{\text {slag }}$ are the mass transfer coefficients in the steel and the slag phases; $m_{\text {steel }} \rho_{\text {steel }} /$ $\left(m_{\text {slag }} \rho_{\text {slag }}\right) \approx 30.1$.

Since small values of $L$ cause $m_{\mathrm{eff}}$ to be significantly smaller than $m_{\text {steel }}$, desulfurization kinetics may be expected to be slower (smaller value of $m_{\mathrm{eff}}$ ) for the lower-basicity slags. However, $m_{\text {eff }}$ was found to be similar to that for the higher-basicity slags even in the case where the low-basicity slag was used, for the steel with the higher silicon content (experiment LB2), as illustrated by Figure 15.

This figure compares measured desulfurization (for the low-basicity slag, high-silicon experiment LB2) with the predictions of the simplified model, using $m_{\mathrm{eff}} A=0.2 \times 10^{-6} \mathrm{~m}^{3} / \mathrm{s}$ (as for the other experiments). Also shown is the predicted desulfurization when using the full model (considering slag and steel mass transfer as potentially rate limiting). Everything else being equal, desulfurization would be (slightly) slower if slag mass transfer were included as a rate-limiting step, as in the full model; in line with this principle, the full model gives the same desulfurization line only if a slightly larger mass transfer coefficient is used than in the simplified

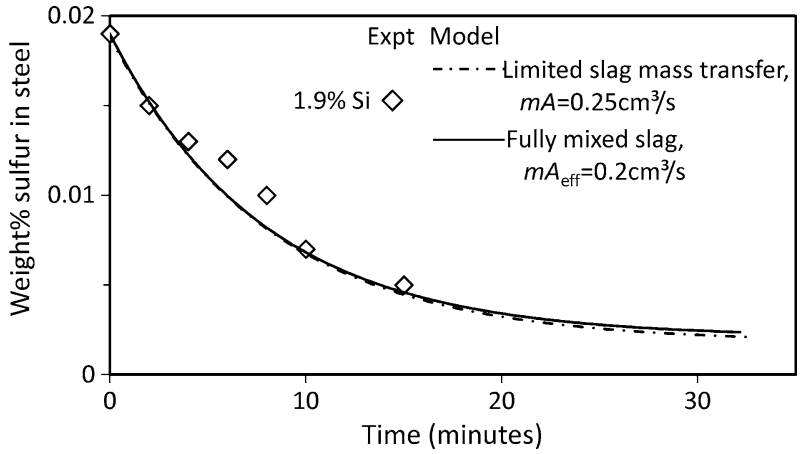

Fig. 15-Experimental data for change of sulfur in steel (data points) compared with the predicted desulfurization using the full model including slag mass transfer, and using the simplified model (steel mass transfer only); high-silicon steel (initial silicon content $1.9 \mathrm{wt}$ pct) in contact with lower-basicity slag (39.9 pet $\mathrm{CaO}$, 39.9 pct $\mathrm{Al}_{2} \mathrm{O}_{3}, 8.9$ pct $\mathrm{SiO}_{2}, 11.1$ pct $\mathrm{MgO}$ ).

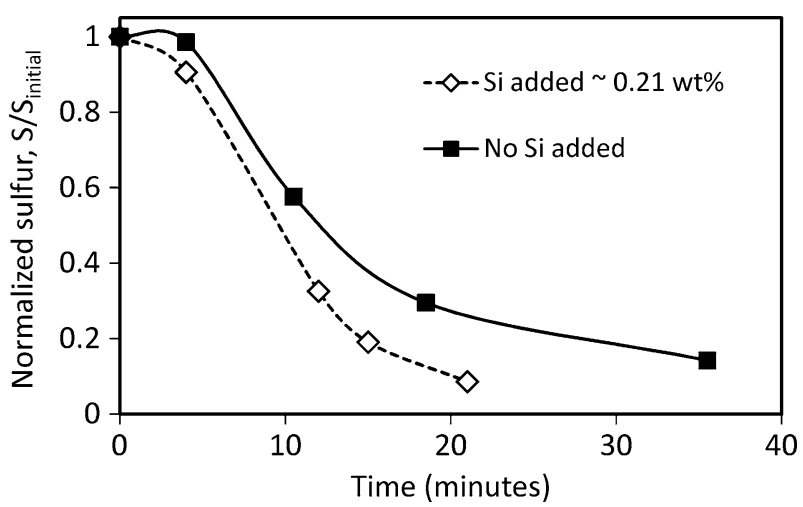

Fig. 16-Plant trial, operator 1: change of normalized sulfur content with time for a heat with $\mathrm{Si}$ added at the beginning of ladle treatment, and another with no Si added.

model $\left(m_{\text {steel }} A=0.25 \times 10^{-6} \mathrm{~m}^{3} / \mathrm{s}\right.$ for the full model, compared with $m_{\mathrm{eff}} A=0.2 \times 10^{-6} \mathrm{~m}^{3} / \mathrm{s}$ for the simplified model). This small difference is in line with Eq. [2] and the predicted equilibrium sulfur distribution 
coefficient for this case, which is $L_{\mathrm{S}}=240$; Eq. [2] shows that this $L_{\mathrm{S}}$ is sufficiently large to insure that $m_{\mathrm{eff}}$ is only slightly smaller than $m_{\text {steel }}$. Even for this case of the relatively low-basicity slag, limited slag mass transfer has only a minor effect on desulfurization kinetics.

However, when this lower-basicity slag was in contact with low-silicon steel, the effective mass transfer coefficient was found to be approximately half that for the other cases (Figure 4 and Table IV). This is also in line with Eq. [2]: For the low-Si, low-basicity experiment, the predicted aluminum concentration at the interface is very low $\left(\sim 0.005 \mathrm{wt}\right.$ pct) and (hence) the predicted $L_{\mathrm{S}}$ is

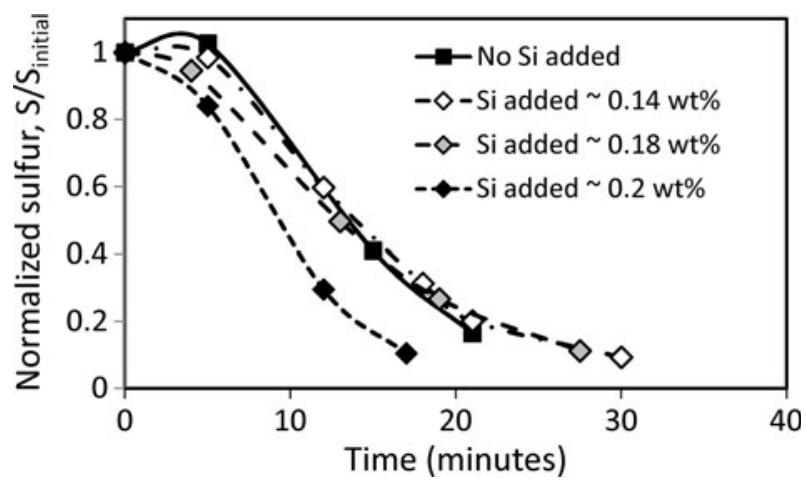

Fig. 17-Plant trial, operator 2: change of normalized sulfur content with time for heats with $\mathrm{Si}$ added at the start of ladle treatment and a heat with no $\mathrm{Si}$ added. Ladle stirring was observed to be poorer for the 0.14 and 0.18 pct Si heats.

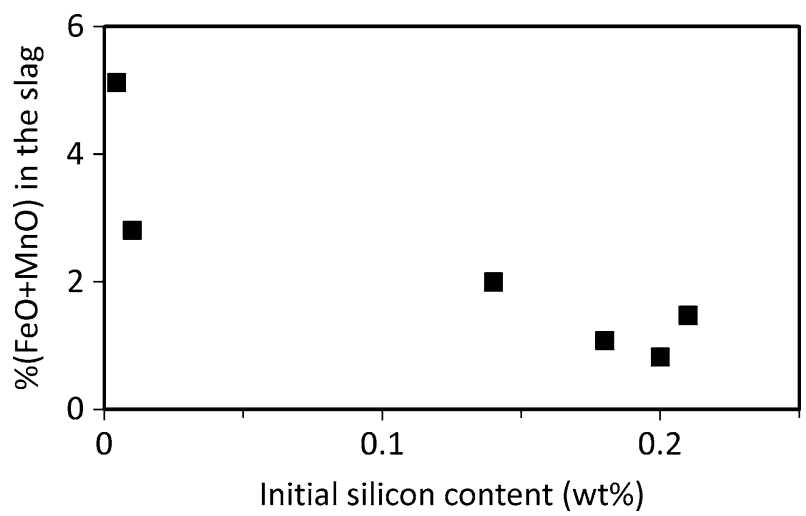

Fig. 18-Relationship between pct $(\mathrm{FeO}+\mathrm{MnO})$ in slag and the initial $\mathrm{Si}$ content in steel (first slag and steel samples taken after deoxidation). only 27. Substitution of this $L_{\mathrm{S}}$ in Eq. [2] gives $m_{\text {eff }} / m_{\text {steel }}=0.5$, which is in line with the fitted relationship (Figure 4 and Table IV). The conclusions are that slag mass transfer is rate limiting (for desulfurization) only rarely, and that - even in the cases where slag mass transfer is rate limiting - the simplified model can be used, provided that the effective mass transfer coefficient is adjusted using Eq. [2].

\section{F. Experimental Results: Conclusions}

The findings of the experimental results are as follows:

- As predicted theoretically, the rate and extent of desulfurization increase with the increase of the initial

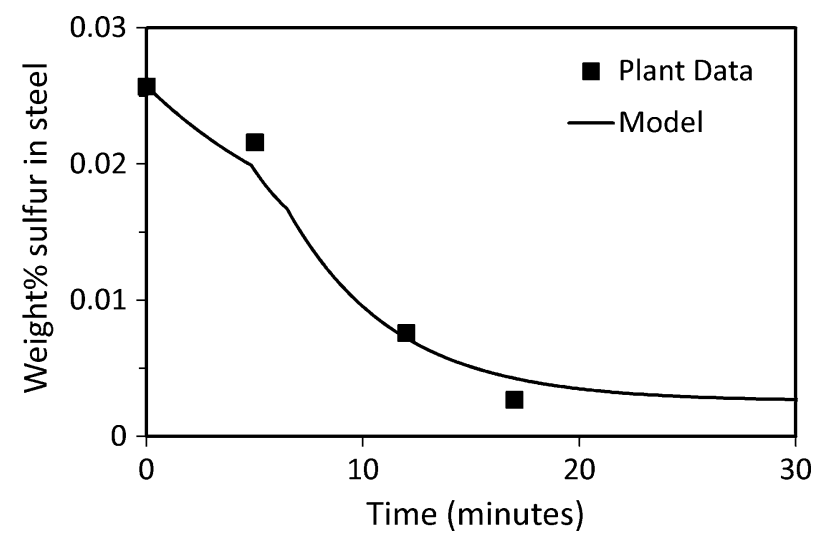

Fig. 20-Comparison of plant data with kinetic model: change of sulfur content with time for a Si-containing grade.

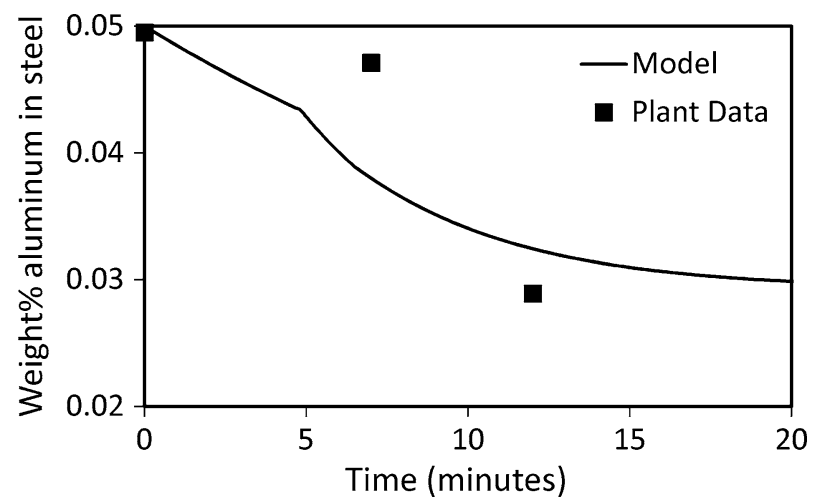

Fig. 21-Comparison of plant data with kinetic model: change of aluminum content with time for a Si-containing grade.

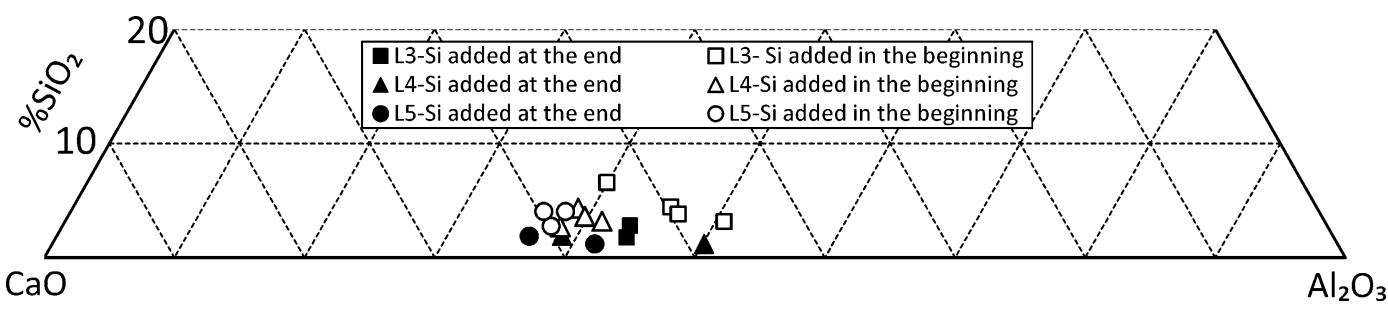

Fig. 19- Change in slag compositions (mass pct) for both the Si-containing heats (open symbols) and heats with no Si added (filled symbols); total $\mathrm{CaO}, \mathrm{Al}_{2} \mathrm{O}_{3}$, and $\mathrm{SiO}_{2}$ content normalized to 100 pet. 
Si content, and this effect of silicon is smaller for slags with higher basicity (higher sulfide capacity).

- The model results are in agreement with the experimental data for the change in sulfur, silicon, and aluminum contents with time, if the FactSage predictions of slag activities are used.

- The experimental results demonstrate that if the silicon content in the steel is high enough, silicon can reduce alumina from the slag and thus the steel melt will pick up aluminum.

- For most of the slag compositions used in the experiments, the overall mass transfer is only limited by the steel phase and rate limitation by slag phase mass transfer can be neglected for most practical cases.

- Mass balance calculations on experiment results support the basis of the model and confirm that, with respect to aluminum consumption, silica reduction is the main aluminum-consuming reaction and the desulfurization reaction is only a secondary consumer of aluminum.

\section{PLANT DATA ANALYSIS}

\section{A. Plan of Plant Trials}

Plant trials were conducted in collaboration with an EAF producer to test the effect of silicon on the desulfurization of Al-killed steels. The practice in this plant was to deoxidize the slag completely before the onset of the ladle-refining process; typical total $\mathrm{FeO}+$ $\mathrm{MnO}$ contents of the slags were 1 to 2 pct.

The heat size was 165 tons and about 2250 to $3150 \mathrm{~kg}$ of slag was used per heat. However, the slag was gradually formed during the desulfurization process through batch additions of lime and fluxes throughout ladle treatment. The plant trials were planned such that for some heats of Si-containing grades $(0.25$ to 0.3 wt pct $\mathrm{Si}$ ), all the $\mathrm{Si}$ was added with aluminum and the fluxes at the beginning of the ladle-refining process, whereas for the rest of the heats, no Si was added until the desulfurization target for the grade had been achieved. For some other heats, half of the required silicon was added (as silicomanganese) 2 minutes after lime addition and the rest added (as ferrosilicon) after the desulfurization target had been achieved.

\section{B. Plant Trial Results}

The progress of desulfurization with time is compared for the Si-containing grades with all the $\mathrm{Si}$ added in the beginning and all the $\mathrm{Si}$ added after the desulfurization reaction. The results obtained by two different operators are shown separately (Figures 16 and 17); Si contents noted in the figures refer to samples taken 2 minutes after addition of the aluminum, fluxes, and the first batch of lime to the heat. Temperature and stirring rate were two process parameters which were found to be difficult to maintain constant between different heats; differences in these were taken into account when analyzing the plant data.
Figure 16 clearly demonstrates that for operator 1 , the rate and the extent of desulfurization are higher for the grade with $\mathrm{Si}$ added $(\sim 0.21$ wt pct $\mathrm{Si})$ compared with the grade with no $\mathrm{Si}$ added $(\sim 0.01 \mathrm{wt}$ pct $\mathrm{Si})$. This difference was found even though the Si-containing heat had a lower temperature [15 K $\left(15^{\circ} \mathrm{C}\right)$ lower], smaller consumption of $\mathrm{Al}$ (approximately 6 pct less), and less consumption of slag deoxidants (17 pct less) than the grade with no Si added.

The results in Figure 17 (heats of operator 2) show similar increases in the rate and extent of desulfurization increasing for a higher initial Si content. In the case of operator 2, the lower temperature of the grade with no $\mathrm{Si}$ added [about $55 \mathrm{~K}\left(55^{\circ} \mathrm{C}\right)$ lower than for the grades with 0.2 wt pet $\mathrm{Si}$ ] could also have contributed to the lower rate and smaller extent of desulfurization. However, calculations indicate that, in the absence of any effect of $\mathrm{Si} / \mathrm{SiO}_{2}$, this effect of lower temperature would have been more than offset by the higher $\mathrm{Al}$ addition to this heat (approximately $14 \mathrm{pct}$ higher addition of $\mathrm{Al}$ than the average $\mathrm{Al}$ addition for the heats with $\mathrm{Si}$ added). Another interesting observation is that, even though the heats with 0.14 and $0.18 \mathrm{wt}$ pet Si had poor stirring and smaller lime and aluminum additions than the heat with no $\mathrm{Si}$ added, these grades showed similar or higher rates of desulfurization than the heat with no $\mathrm{Si}$ added. This highlights the beneficial effect of silicon even within the scatter of plant results.

The reducing effect of silicon additions is also evident in the $\mathrm{FeO}+\mathrm{MnO}$ content of the slag: Figure 18 shows the pct $(\mathrm{FeO}+\mathrm{MnO})$ in the first slag sample (analyzed using XRF) against the Si content of the corresponding steel sample. Clearly, $\mathrm{Si}$ in the steel contributes to reducing $\mathrm{FeO}$ and $\mathrm{MnO}$ from the slag. The reducing effect of silicon would inevitably result in formation of silica, which would report to the slag. The resulting increased $\mathrm{SiO}_{2}$ content of the slag was indeed found when comparing slag analyses for the Si-containing and no-Si heats during the course of the desulfurization reaction (Figure 19). In Figure 19, the labels L3, L4, and L5 refer to samples taken at increasing times, with L3 taken immediately after deoxidation. Slags from the heats where $\mathrm{Si}$ was added at the beginning of ladle treatment consistently contained more silica in the heats where no $\mathrm{Si}$ was added at the start. However, the resulting differences in sulfide capacity were small compared with the large effect of $\mathrm{Si}$ on the desulfurization equilibrium.

\section{Comparison with Kinetic Model}

For comparison with plant data, the kinetic model was extended to take into account the following:

- Al consumed in the deoxidation reaction (simple mass balance).

- The gradual formation of the slag and the addition of lime in batches.

- The change in the stirring rate during the ladlerefining process (once most of the fluxes had been added, the argon flow rate through the stirring plugs 
was increased, from 0.4 standard $\mathrm{m}^{3}$ per minute to 1 standard $\mathrm{m}^{3}$ per minute).

The results from the kinetic model agree with the plant trial results (Figure 20 (change in sulfur) and Figure 21 (change in aluminum with time)). In Figure 20, there are two changes in the slope of the predicted desulfurization curve. The first slope change reflects the increase in the stirring rate and the second change is due to the second batch of lime added to the slag (which increased the driving force for desulfurization). (As Figure 21 indicates, the second batch of lime addition was predicted to have little effect on aluminum fade.)

\section{Plant Trial Conclusions}

Conclusions from the plant trial are as follows:

- As predicted, the rate and extent of desulfurization increased with increased initial Si content. Hence, in the ladle-refining process, adding all the silicon with the aluminum and the fluxes at the start of ladle treatment could save considerable processing time.

- For the heats with silicon added at the start of the ladle treatment, the aluminum consumption (Al added to the steel and slag deoxidants) was considerably lower than in heats where the silicon was added at the end; this confirms that silicon trim additions can substitute aluminum trim additions.

\section{ACKNOWLEDGMENTS}

We are grateful to Dr Eugene Pretorius, Mr Helmut Oltmann, and the industrial members of the Center for Iron and Steelmaking Research for their support of this project.

\section{REFERENCES}

1. D. Roy, P.C. Pistorius, and R.J. Fruehan: Metall. Mater. Trans. B. doi:10.1007/s11663-013-9813-0.

2. C.W. Bale, P. Chartrand, S.A. Degterov, G. Eriksson, K. Hack, R. Ben Mahfoud, J. Melançon, A.D. Pelton, and S. Petersen: CALPHAD, 2002, vol. 26, pp. 189-228.

3. D. Roy, P.C. Pistorius, and R.J. Fruehan: AISTech 2011 Proceedings, Association for Iron \& Steel Technology, Warrendale, PA, 2011, vol. 1, p. 1357.

4. M.M. Nzotta, D. Sichen, and S. Seetharaman: Metall. Mater. Trans. B, 1999, vol. 30B, pp. 909-20.

5. M. Andersson, M. Hallberg, L. Jonsson, and P. Jönsson: Ironmak. Steelmak., 2002, vol. 29, pp. 224-32.

6. H. Ohta and H. Suito: Metall. Mater. Trans. B, 1998, vol. 29B, pp. 119-29.

7. Y. Chung and A.W. Cramb: Metall. Mater. Trans. B, 2000, vol. 31B, pp. 957-71. 